\title{
The influencing factors of architectural composition and the arrangement of human settlement in Orchid Island
}

\author{
C.-J. Chen \& S.-T. Kuo \\ Graduate Institute of Urban Development and Architecture, \\ National University of Kaohsiung, Taiwan
}

\begin{abstract}
Orchid Island (Lan-Yu) is off Taiwan's southeast coast; it is mostly populated by an aboriginal people called the Tao. There are six tribes containing three thousand people who inhabit the island with a primitive but sustainable way with their own unique human settlement, living culture and society system. The subterranean building is the most particular architectural element of the island. Moreover, the typology, as well as the arrangement of such buildings, is highly efficient and practical, corresponding with the local environment and the landscape of the island.

Although the space of settlement and the land use of the island changes gradually due to the socio-economic factor, the traditional subterranean buildings still survive and are used largely in the tribes of Langdau and Yehyin. However, we can explicitly recognize some physical differences of these buildings, such as the orientation, roof angles and even the space and site arrangement.

The goal of this research is to specify the influencing factors of the mentioned differences of the buildings. The content of the research consists of:

1. a field investigation on the configuration of buildings and the difference between two tribes;

2. the correlation analysis and the comparison study between the settlement arrangement and the composition of traditional buildings.

By means of document analysis and filed investigation, this research concludes that the geological or climatic conditions should be the main influencing factors of buildings. More scientific analysis and discussion should be systematically involved to clarify the goal of the research.
\end{abstract}

Keywords: Orchid Island, subterranean building, environmental factors. 


\section{Introduction}

Orchid Island (called Lan-Yu in Mandarin) is off Taiwan's southeast coast. Three thousand Tao people inhabit the island with a unique human settlement, living culture, society system and natural landscape, which are totally different from the other peoples of the main Taiwan Island. Orchid Island is a volcanic island formed by magma erupting from the ocean floor. It used to be called "Redhead Island" because the peaks of the mountains at the northwest corner of the island resemble red human heads in the crimson rays of the setting sun. The name of Orchid Island refers to the many wild orchids that once grew on this island where the climate is humid and rainy. The large variety of ecosystems and the special culture are the main characteristics.

\section{Configuration of human settlements}

Orchid Island consists of six villages that are distributed around the coast of the island. They are Yayu (Yeyou), Iraralay (Langdau), Iranumilk (Dongqing), Ivarinu (Yeyin), Imourud (Hongtou) and Iratai (Yuren), see Figure 1. The villages are situated near by the port, and are ringed by the paddy field where taro is the primary crop for the Tao people. The buffer zone between the seashore serves as the shipyard, cemetery and desolation. Behind the villages there are mountains and the forest that provide a rich water resource and construction materials, respectively, see Figure 2.

\section{Vernacular architecture}

The original Taos' dwellings were built partially underground and had a comprehensive content. A "complete" traditional dwelling consists of three

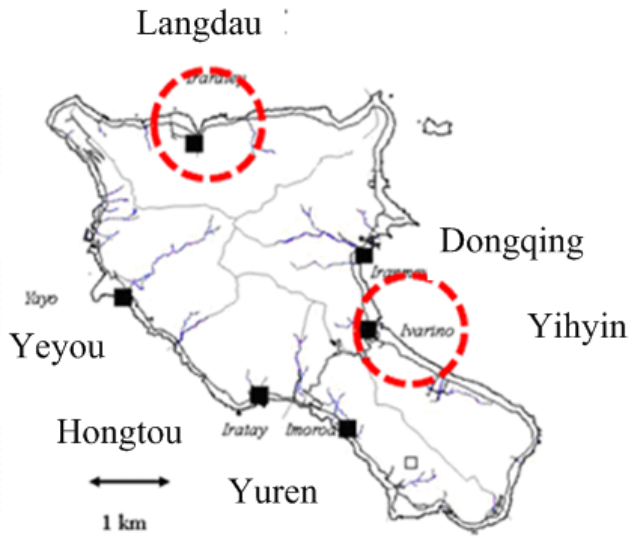

Figure 1: $\quad$ Orchid Island [1]. 


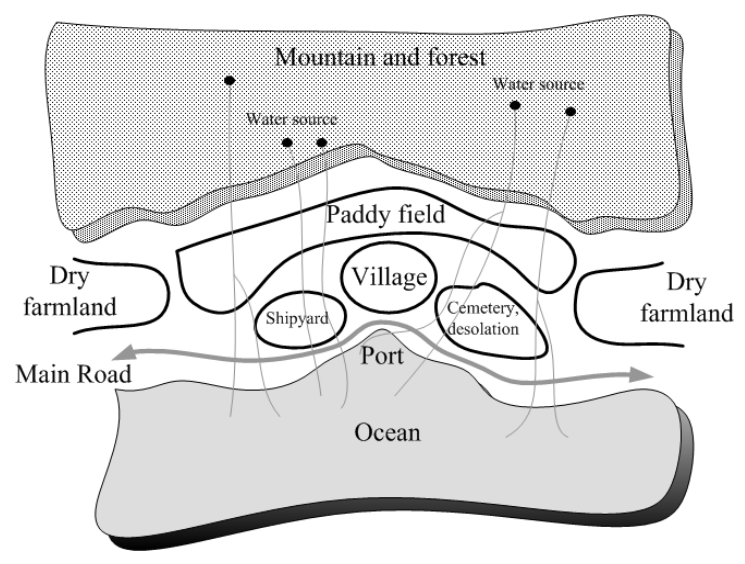

Figure 2: $\quad$ Composition of human settlement [2].

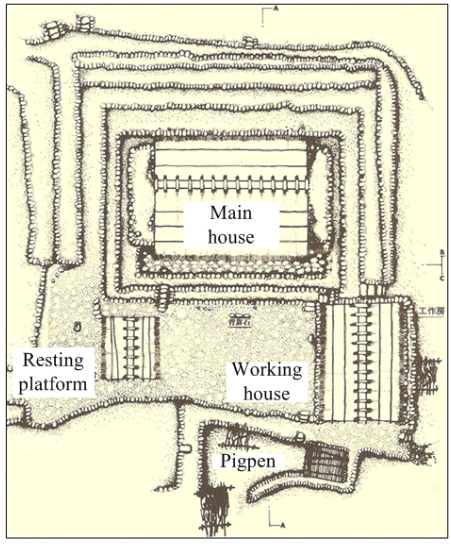

Figure 3: Arrangement of a living unit.

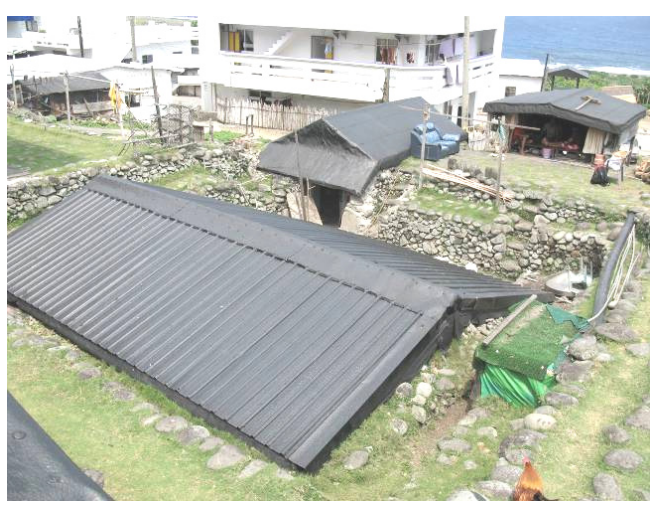

Figure 4: Three elements of a dwelling.

elements: a working house, a resting platform and a subterranean main house (Figures 3 and 4). The main house is dug into the earth as a spacious pit, so that the roof is nearly level with the surface of the surrounding earth. The boundary between houses is walled by cobbles in a natural way. The efficient drainage system rarely causes flooding in the village. For Tao people, the subterranean house not only shelters their families against natural disasters, especially typhoons during the summer as well as torrid heat, but it also symbolizes the vital tradition and social status of adult males in the tribe. The various sizes of dwelling in the village signify the life evolution of family and also reflect the practical changes of function needs [2]. 


\subsection{Composition of dwelling}

Figure 5 shows a complete dwelling unit formed by three elements for Tao people. The subterranean main house is situated in the middle of the site with a lower ground level than the others. The sizes of such a main house symbolize the social status, as well as the construction capacity, of the owner. The working house (Magaran) signifies a temporary and functional space for young people. It serves as an accommodation and working space when young people become independent, but yet unable to build a main house. The resting platform provides mainly a communication and relaxing space. In general, all buildings are placed facing the sea and are distributed alone the contour of the inclined land. Although modern materials and techniques are accepted by local construction, the traditional components of a dwelling remain intact. Figure 6 shows a significant difference in roof material between actual houses and old houses.

\subsection{Eco-design and social meaning}

The meanings of traditional dwellings are on the one hand, a good correlation with the environmental conditions and on the other, the reflection of the family chronicle in space. The subterranean main houses provide an ideal shelter against

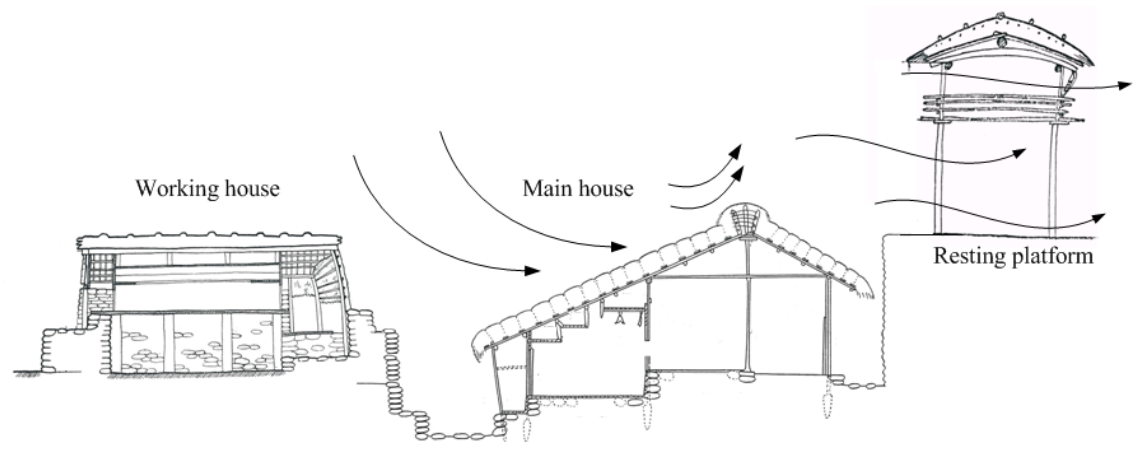

Figure 5: Three elements of a traditional dwelling.
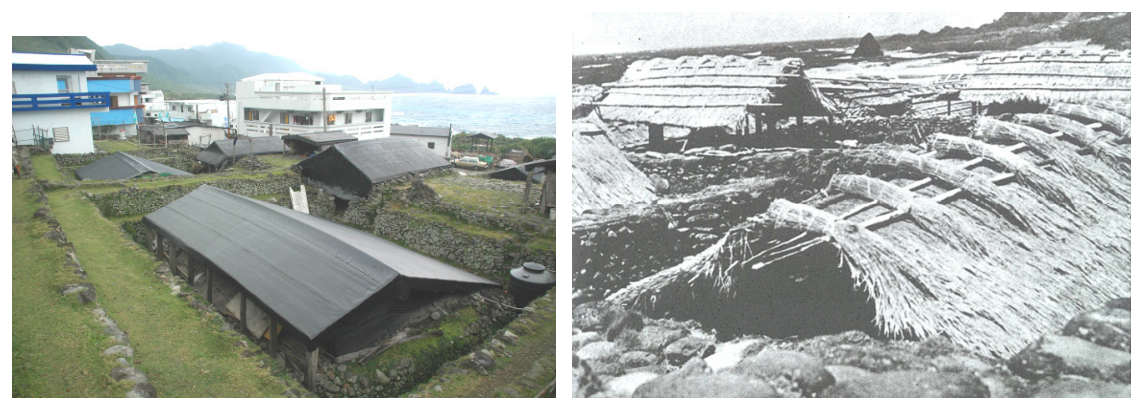

Figure 6: $\quad$ Restored dwelling in 2008 (left) and old dwelling in 1920 (right). 


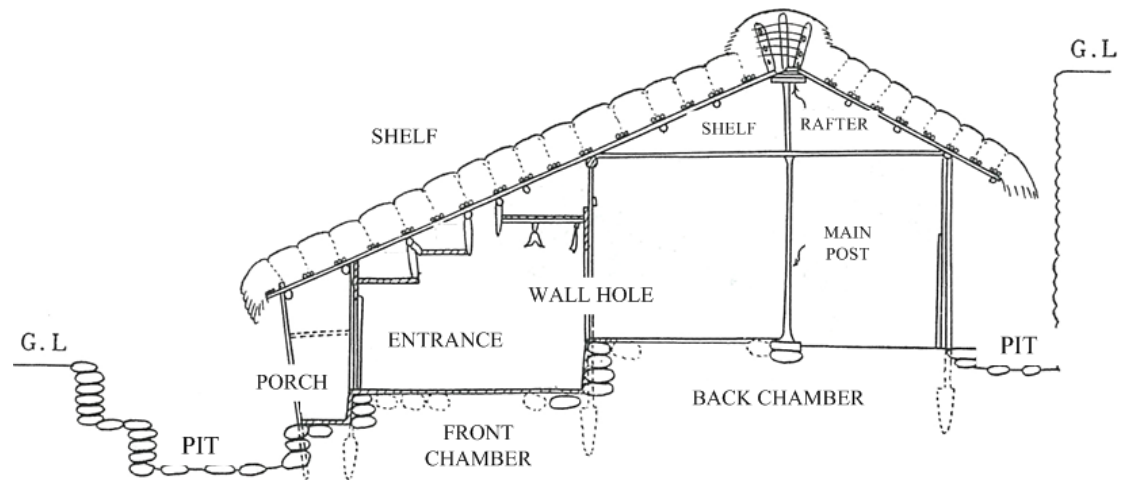

Figure 7: Profile of a main house [3].

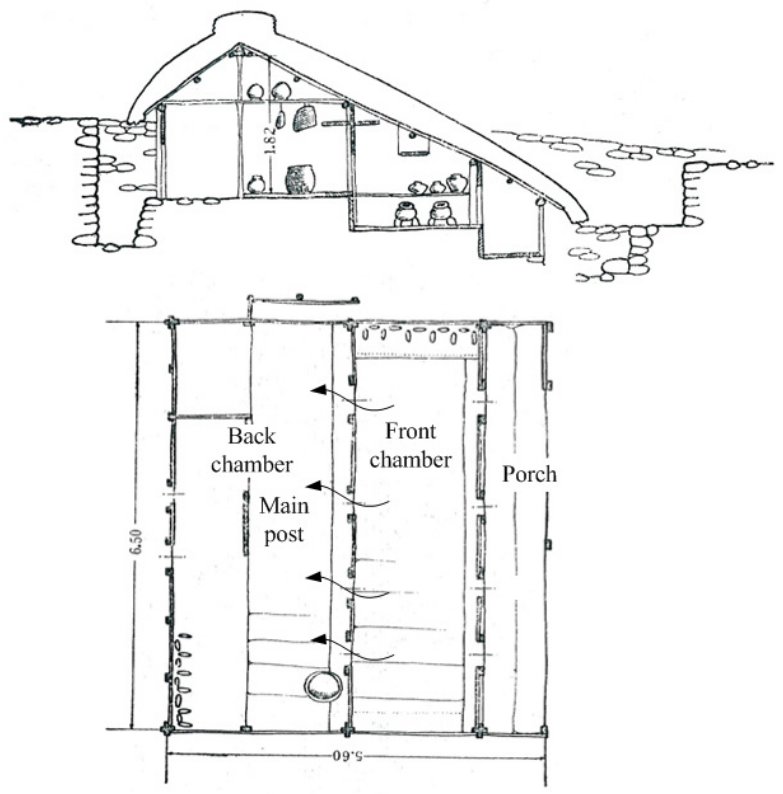

Figure 8: Arrangement of a main house [3].

typhoons, which are the most destructive disaster to affect the island. Although the buildings are constructed under ground level within a pit, the efficient drainage can prevent the problem of flooding (Figure 7).

In accordance with the traditional process of construction, the pit for the main house should be observed and evaluated for several years to assure the perfect drainage function. The different depth of pits is thus defined by considering this practical experience and geological condition. At the same time, main houses signify the maturity and the riches of family for Tao people. The number of 
entrance doors is proportional to the economic capacity and social status of the family. Most main buildings have three or four entrance doors.

The working houses exist in all families and represent a transitional building type. When the young commence their independence, these semi-subterranean piloti houses support their simple living needs before they construct their main house. The working house is also a place for working in the daytime and for storage.

The resting platforms are built usually on the highest place in the village. This pavilion like structure consists of wooden post-beam and thatch roof. It serves not only as a cooling and relaxing space for people, but also as an important social place for both family and guests. There is no standard height and form for the resting platform. It serves also as an observatory of the village and an ideal place for napping in the hot summer. Different forms of resting platform are shown in figures 10 and 11 [4].

\section{Comparative study}

Two villages, Yehyin and Langdau, were selected as study cases because of their originality and intact situation regarding the integrity of their settlements. This study focuses on the comparison of settlement arrangement as well as dwelling type.

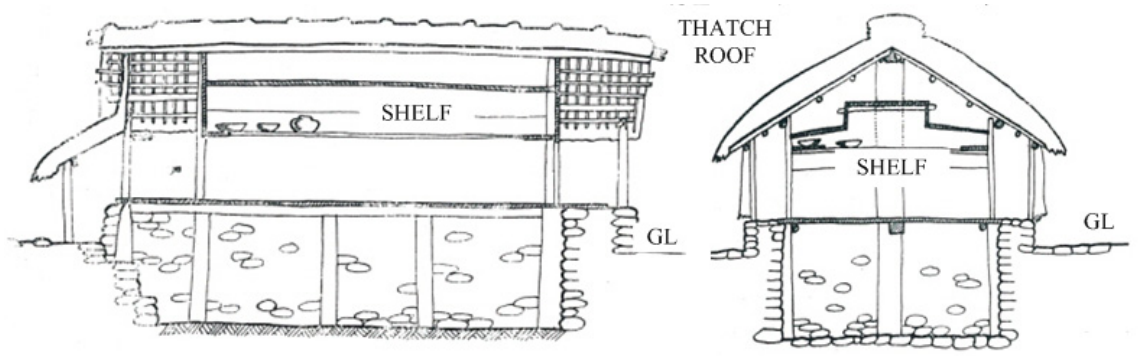

Figure 9: Working house [3].
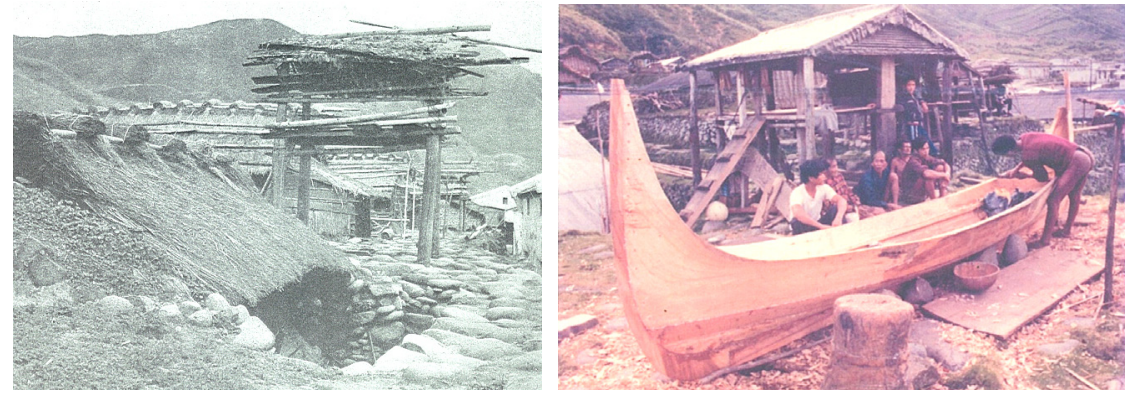

Figure 10: Resting platform in 1930. Figure: 11: Resting platform in 1960. 


\subsection{Settlement comparison}

Situated on the eastern side of the island, Yehyin village began to extend its living territory in 1960, instead of demolishing the original site. The new site is located just parallel to the original old village. Almost every family kept their own traditional dwelling, or at least the land inherited from their ancestors (Figures 12 and 13). Neither landscape nor traditional dwelling is rudely changed by the modern policy of land use. Figure 13 shows the traditional dwellings adjoining new buildings in Yehyin.

Langdau village is located on the north of the island. Due to its limited territory, the village has had to gradually transform its building type and overall landscape. In addition, the village extended its new quarter in the mountain direction. The old part of the village thus shows a typical transitional appearance. The risk of this development is that not only the traditional organization of

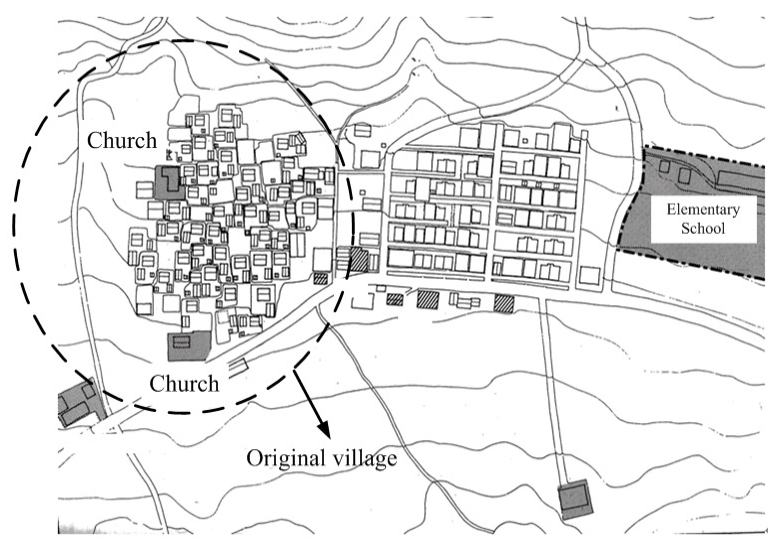

Figure 12: $\quad$ Yehyin village (left) [4].

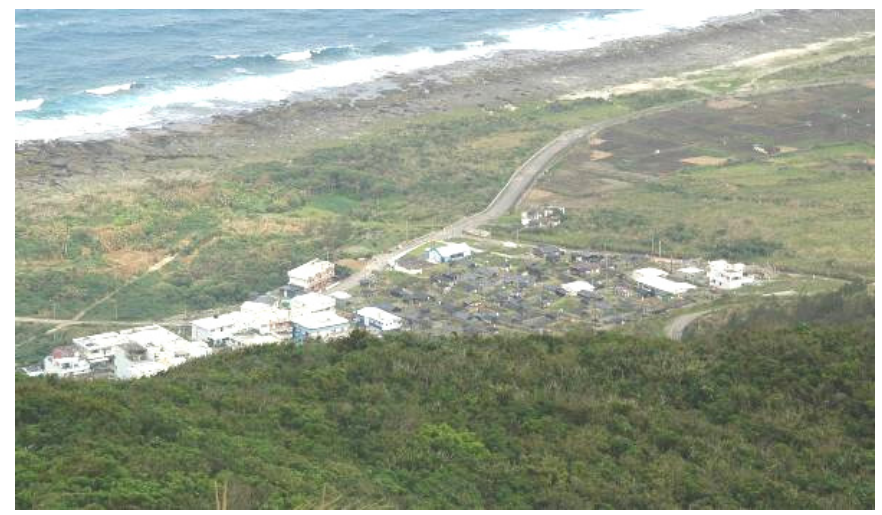

Figure 13: The original village is on the left-hand side of new one (right). 


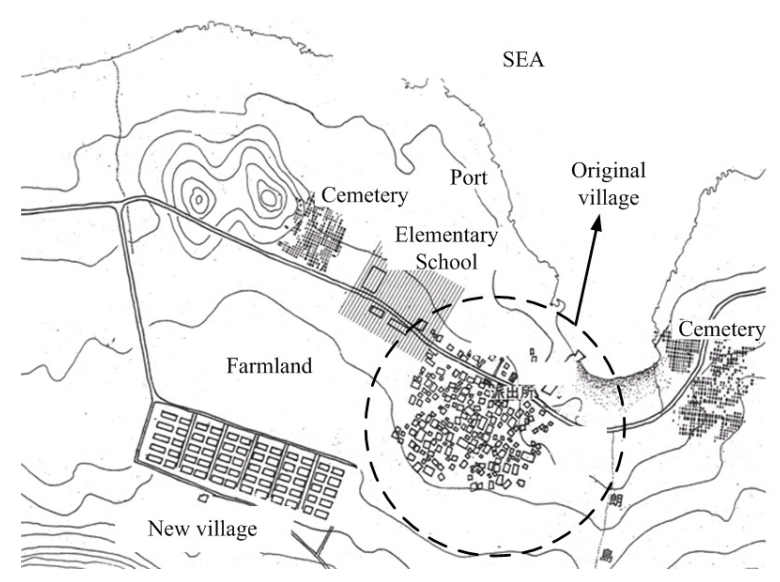

Figure 14: Configuration of Langdau village [4].

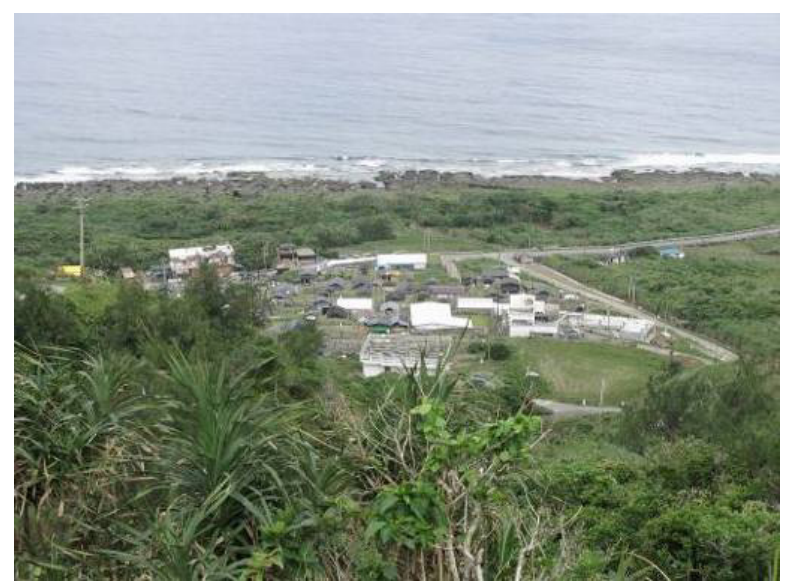

Figure 15: Langdau village.

human settlement is weakened, but also the traditional living culture is interrupted. Figures 14 and 15 show the original village located on a narrow site between the seashore and the mountains.

The common principles of the arrangement of both villages are: (1) original villages consist of traditional dwellings that are randomly dispersed but respond well to their environmental, geological and topographic conditions; (2) gradual transformation of the village forces villagers to zealously preserve their traditional living culture and to reflect the values of traditional settlement.

\subsection{Architectural comparison}

Since typhoons are the most serious disaster for the island, the typology of all main houses explicitly reflects this consideration. Nevertheless, different roof 
slopes and depths of pit and interior chamber can be observed between Yehyin and Langdau villages. The southwest monsoon and northeast monsoon are also considered for the roof design of main houses. The slopes of all houses vary thus between $65^{\circ}$ and $70^{\circ}$. The length of front roofs is always twice that of the back ones due to the position of the ridge or the distributed proportion between front and back chambers.

The depth of the pit is another important issue. We found that the depths of the ground of Langdau are more obvious than those in Yehyin. In the studied case, the depth is $281 \mathrm{~cm}$ for Lanmgdau and $170 \mathrm{~cm}$ for Yehyin. The height of the main posts is $200 \mathrm{~cm}$ and $115 \mathrm{~cm}$, respectively. Figures 16 and 17 show the comparison of the different main houses of Yehyin and Langdau.

The inclination of the land in Yehyin village is $15 \%$ more than that in Langdau village. In order to obtain the same dimension of the main house, it seems reasonable that the pit of the main house should be deeper in Yehyin village. In fact, the result is on the contrary in accordance to the filed investigation.

In terms of geological data of Orchid Island, Yehyin village is situated on Talus Deposit, and Langdau village is built on Alluvium (fluvial fan). Due to the higher permeability of land of Talus Deposit, it is relatively easy to create the pit of the main house in Yehyin with a shallower depth. Alluvium contains coarse
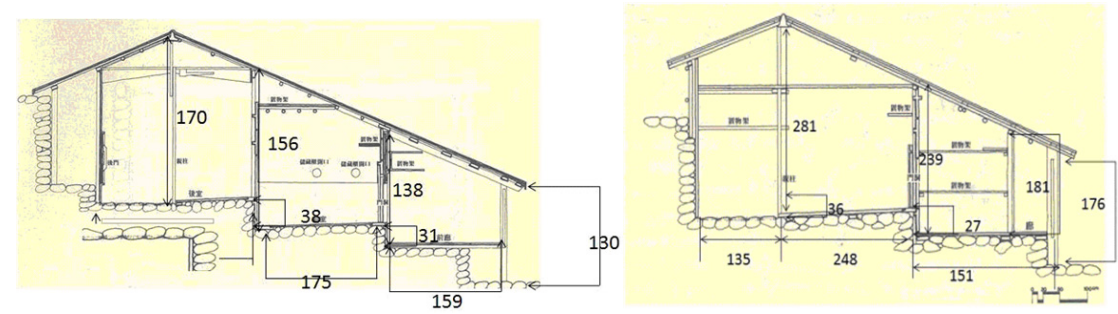

Figure 16: Profiles of a traditional main house of Yehyin (left) and Langdau (right).
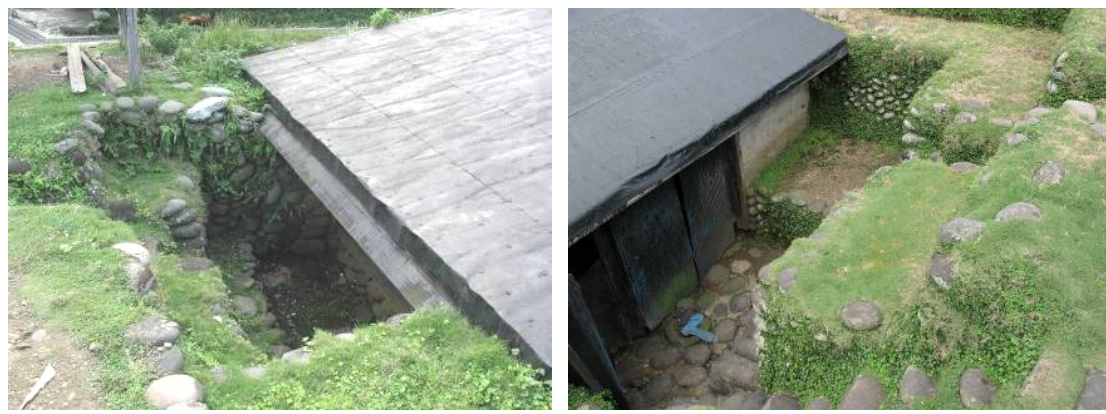

Figure 17: Different pit depths of a main house in Yehyin (left) and Langdau (right). 

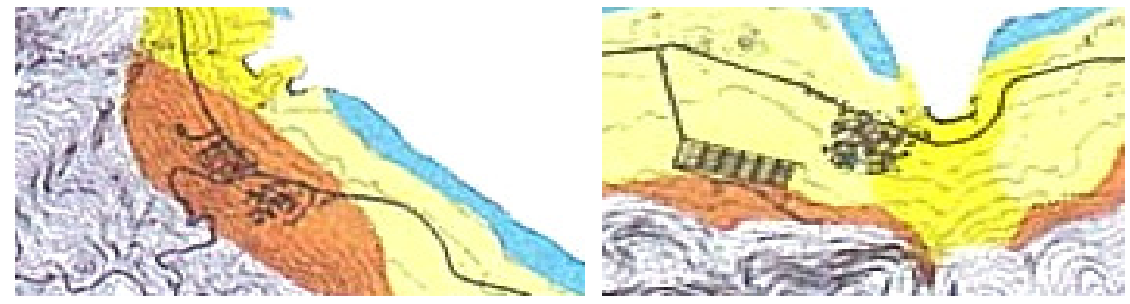

Figure 18: Geological conditions for Yehyin (left) and for Langdau (right).
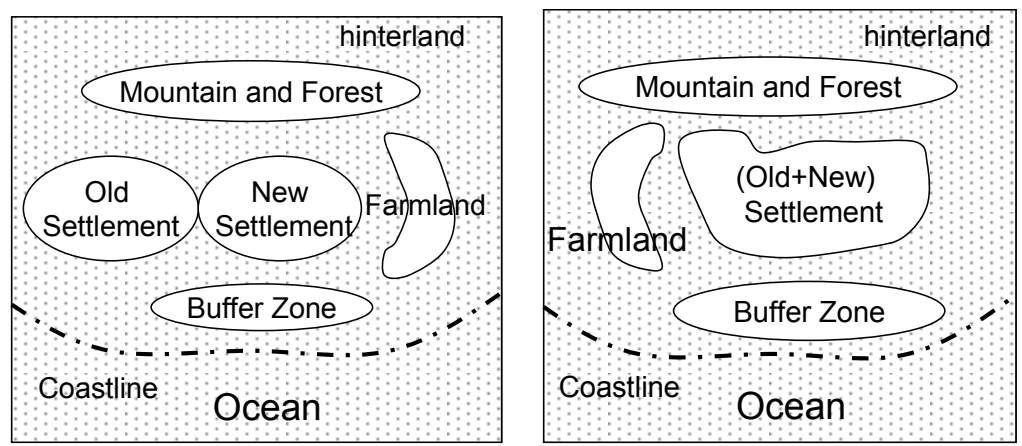

Figure 19: Modes of transition for Yehyin (left) and Langdau (right).

sand and gravel deposited by streams and rivers, which can provide an ideal storage medium for water. Consequently, people in Langdau are obliged to dig the pit deeper before constructing the main house. Figure 18 explains the different geological conditions between Yehyin and Langdau.

\subsection{Space transformation}

Figure 19 shows the different modes of transformation for Yehyin and for Langdau, respectively. Yehyin kept the old settlement and added the extension. Developing in another direction, Langdau transformed and enlarged the village based on the original one. All farmlands and buffer zones (cemetery, shipyard and desolation) are thus reduced. However, the principle of village organization remains unchanged.

For the living space, although the islanders of Orchid Island actually live in a transforming new environment, they are yet conscious of their traditional living style. In order to keep an extraordinary landscape with traditional texture and atmosphere of the village, the people restore or remodel their old dwellings using the subsidy provided by the government. The main construction material (wood) and erection method (handmade) should be respected in traditional ways. The appearance of the building should be persisted without distinct change.

Figure 20 describes two examples in which we can find the basic elements of the house plan without changing the original characteristic of the building. Features such as the space order (corridor-front room-backroom-kitchen) and 


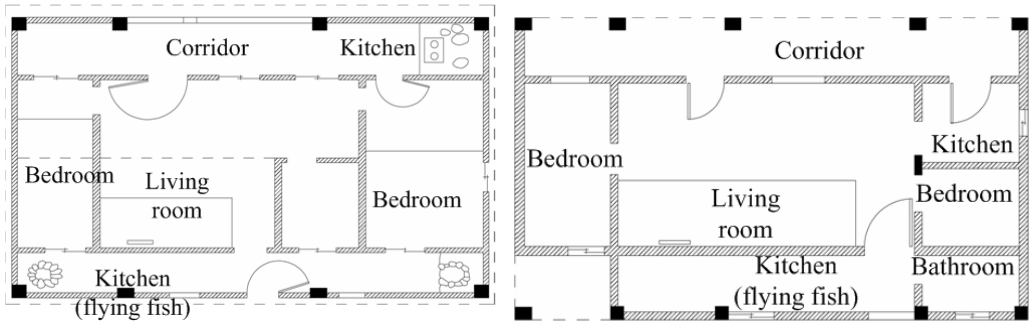

Figure 20: Remodelled house keeping traditional space elements [2].
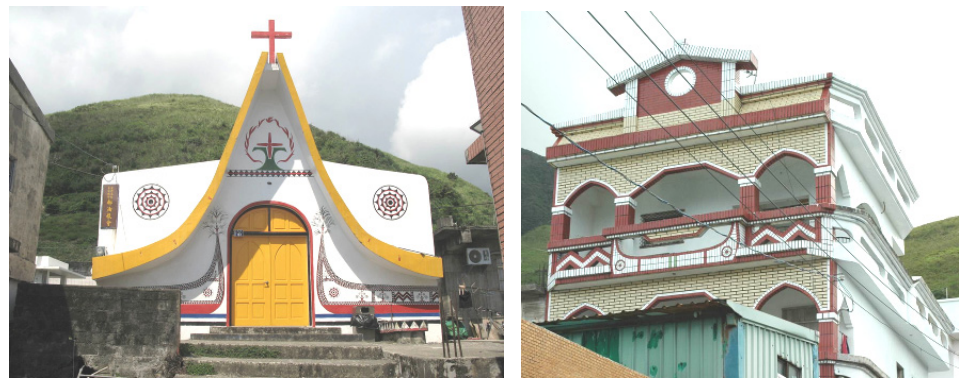

Figure 21: Community church (left) and new modern dwelling (right).

arrangement are intact in remodelled houses. Figure 21 shows the traditional tattoos applied throughout the island, which interpret how local people feel attachment to their own culture.

\section{Conclusion}

After comparing two studied cases in both the arrangement of the settlements and architectural composition, the environmental factors such as climate, geology and topography are concluded as the main influencing factors for the changes in the villages on Orchid Island. Orchid Island is a unique human settlement for Taiwan that is almost intact and represents an important human cultural landscape. The architectural composition on the island also represents the concept of eco-design in primitive time. This will inspire the new architectural development of the island and it is worth involving more quantitative research and discussion on Orchid Island.

\section{References}

[1] Chi-Jen Chen, Course materials of Vernacular Architecture, 2009, National University of Kaohsiung, Taiwan

[2] Szu-Tung Kuo, Chi-Jen Chen (2009), "The Sustainable Dwelling Development of Human Settlement on Orchid Island", Eco-Architecture: Harmonisation between Architecture and Nature, WIT Press 
100 Design and Nature V

[3] Chijiiwa Suketarou, The Dwellings of Aborigines in Taiwan (in Japanese), 1960 Tokyo, 1988 Taipei.

[4] H. Huang, The transition of Yami's Living Culture, 1995, Taipei 